\title{
Estuarine nursery areas provide a low-mortality environment for young bull sharks Carcharhinus leucas
}

\author{
Michelle R. Heupel ${ }^{1,2, *}$, Colin A. Simpfendorfer ${ }^{1,3}$ \\ ${ }^{1}$ Center for Shark Research, Mote Marine Laboratory, 1600 Ken Thompson Parkway, Sarasota, Florida 34236, USA \\ ${ }^{2}$ Australian Institute of Marine Science and School of Earth and Environmental Sciences, James Cook University, Townsville, \\ Queensland 4811, Australia \\ ${ }^{3}$ Fishing and Fisheries Research Centre, School of Earth and Environmental Sciences, James Cook University, Townsville,
} Queensland 4811, Australia

\begin{abstract}
Defining the role and impact of mortality within aquatic populations is often difficult. As a result, we still lack a clear understanding of the level of mortality in natural populations and the role habitat may play in survival. We used long-term acoustic monitoring of neonate bull sharks Carcharhinus leucas in a south Florida estuary to determine mortality rates within this population. Estimates of natural, fishing and total mortality varied among the years examined, but not significantly, suggesting similar survival among years with the majority of individuals (77\%) surviving beyond 18 mo. Compared with other juvenile sharks, mortality rates of $C$. leucas were low. The results indicate that the use of mesohaline estuarine habitats by $C$. leucas may provide benefits that are not present in more marine habitats where their counterparts reside. Use of estuarine regions may be a successful ecological strategy for improving survival because of reduced predation and competition.
\end{abstract}

KEY WORDS: Ecological advantage · Survival · Estuary · Bull shark $\cdot$ Carcharhinus leucas $\cdot$ River

\section{INTRODUCTION}

Mortality plays a crucial role in shaping animal populations, but accurately quantifying this parameter has proven difficult for many aquatic organisms. Long-term approaches that allow the fate of individuals to be followed (e.g. conventional tagging, acoustic monitoring and cohort analysis) are used, but the logistics of data collection mean that they are rarely implemented (Xiao et al. 1999, Gruber et al. 2001, Heupel \& Simpfendorfer 2002). In lieu of direct estimation, indirect methods based on relationships between directly measured mortality of other species and life-history parameters are often used (Simpfendorfer et al. 2005a). Although widely used, these indirect methods are less accurate and different methods produce estimates that vary dramatically (e.g. Simpfendorfer 1999).

Many factors are known to affect mortality rates, including environmental effects (e.g. temperature, salinity and habitat), ecological effects (e.g. competition, predation) and life-history effects (e.g. growth rates and reproductive strategies). Habitat appears to play a key role in determining mortality rates of fish populations. For example, use of nursery areas or specific habitat structures is suggested to improve survival of various fish species (Beck et al. 2001, Wigington et al. 2006, Hook et al. 2007, Gallaway et al. 2009). Despite inroads in understanding survival of juvenile fishes, little data are available regarding directly estimated mortality rates of juvenile sharks and what role habitat may play in their survival.

Many shark species are known to use nursery areas (Springer 1967, Castro 1993, Simpfendorfer \& Milward 1993) and it has been assumed that these areas provide habitats where predation rates are low and as such provide an environment conducive to low rates of mortality (Bass 1978, Branstetter 1990). However, reanalysis of the shark nursery area paradigm of low mortality and high food availability has shown that in 
some instances these conditions are not met (Heupel et al. 2007). For example, Manire \& Gruber (1993) estimated that the mortality rate of $0+$ lemon sharks Negaprion brevirostris in a Bahamian lagoon was 40 to $60 \%$ over their first year. Similarly, Heupel \& Simpfendorfer (2002) estimated that blacktip sharks Carcharhinus limbatus born in a small Florida bay suffered mortality levels of 61 to $91 \%$, including significant levels of fishing, during their first 6 mo of life. In both cases the mortality levels were considered high and predation was thought to be a significant factor in the high levels of mortality, whereas in other nursery areas limited food resources are also known to cause mortality (Duncan \& Holland 2006).

If habitat selection can improve survival of juvenile sharks, differing ecological strategies may produce differing results for the populations that use them. Previous studies of mortality rates in shark nursery areas (e.g. Manire \& Gruber 1993, Heupel \& Simpfendorfer 2002) have examined marine habitats. However, not all sharks use marine nurseries. For example, bull sharks Carcharhinus leucas use nursery areas characterized by low salinity and often inhabit rivers after they are born (Thorson 1971, Snelson et al. 1984, Blackburn et al. 2007). Heupel \& Simpfendorfer (2008) demonstrated that this species has a preference for salinities between 7 and 20 PSU and actively move within estuarine systems as freshwater inflows change. This salinity preference would exclude most other shark species and may substantially reduce the risk of interspecific predation. It could thus be hypothesized that survival of juvenile bull sharks in these habitats

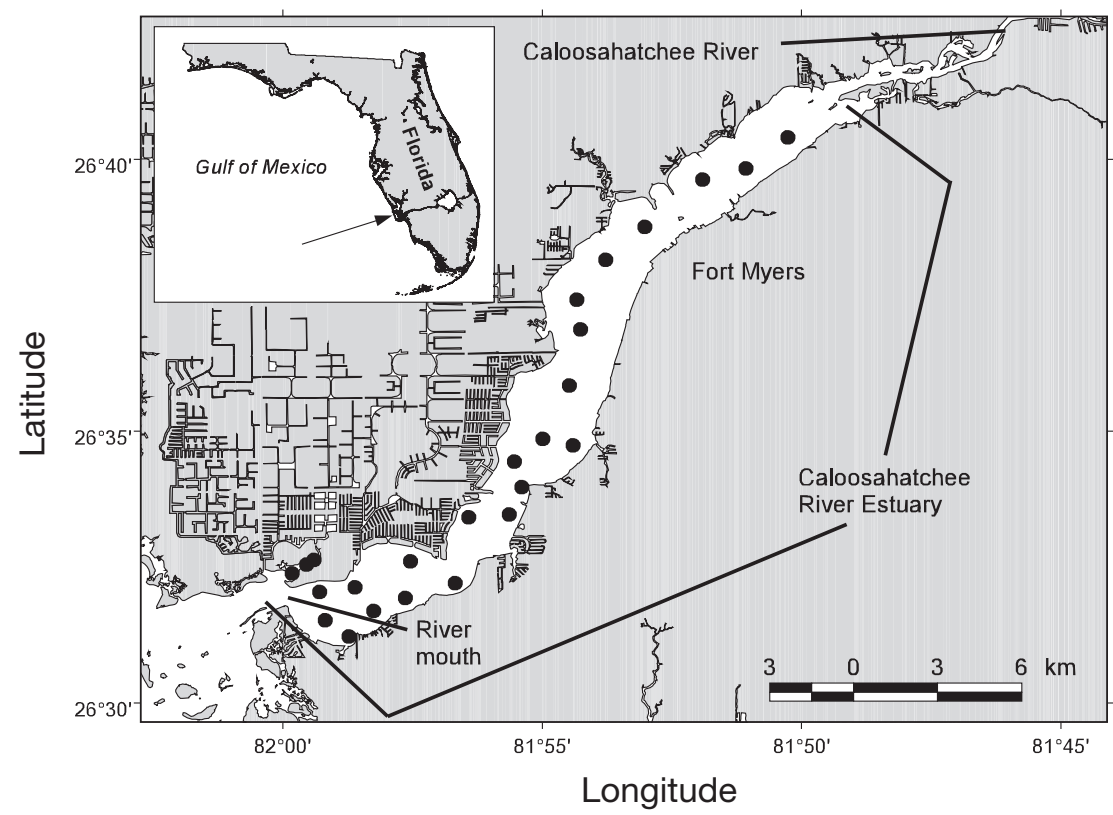

Fig. 1. Caloosahatchee River and its location on the Gulf coast of Florida. Circles represent the locations of acoustic receivers inside the study area would be higher than those of species that occupy marine nursery areas where a wide range of potential predators exist.

The purpose of this research was to (1) determine the level of mortality that occurs within a riverine nursery of bull sharks, and (2) compare the mortality rates of juvenile bull sharks with those of other shark species to test the hypothesis that the use of a habitat that excludes interspecific predation will lead to increased survival rates.

\section{MATERIALS AND METHODS}

Field methods. This study was completed in the estuarine portion of the Caloosahatchee River, Florida, USA, and encompassed approximately $27 \mathrm{~km}$ of river habitat (Fig. 1). The Caloosahatchee River connects Lake Okeechobee to the southwest coast of Florida and has been substantially altered over the past $100 \mathrm{yr}$ (Doering \& Chamberlain 1998). Habitat alterations include an artificial link to Lake Okeechobee, intricate canal systems connected to the main river channel, 3 locks to allow boat passage and dams to regulate flow. Upper reaches of the Caloosahatchee River estuary have natural shoreline and native vegetation, primarily red mangroves Rhizophora mangle. Closer to the mouth of the river the habitat has been largely altered by urbanization, as evidenced by extensive canal developments and shoreline modifications (Fig. 1).

Sharks were captured by longline fishing, weighed, measured, tagged with a dart tag, and surgically fitted with a Vemco RCODE $16 \times 65 \mathrm{~mm}$ transmitter. Transmitters produced a uniquely coded pulse at random intervals between 45 and $90 \mathrm{~s}$. Upon release, movement patterns of sharks were recorded by a series of Vemco 25 VR2 acoustic receivers deployed within the study site (Heupel \& Simpfendorfer 2008, Simpfendorfer et al. 2008, Heupel et al. 2010). The acoustic array allowed sharks to be continuously monitored for the entire period they were present within the study area. Data were downloaded from receivers every 2 to $6 \mathrm{wk}$ and stored in a database. Transmitters had a battery life of approximately 18 mo.

Defining fates of tagged sharks. The fate of individuals was determined from results of the acoustic monitoring data. Similar to methods defined by Heupel \& Simpfendorfer (2002), sharks were classified into 3 categories: (1) survivals - 
individuals that maintained continuous movement within the study site and/or were observed to swim out of the study site; (2) natural mortalities - individuals that ceased movement within the study site or showed movement patterns more rapid than, and inconsistent with, previous or typical movements (this category includes all types of natural mortality, e.g. predation, starvation, disease); and (3) removals (censored) - individuals removed from the study site because of factors other than natural mortality or swimming out, such as harvest by fishermen. These individuals were typified by loss of signal detection from the animal while it was within the acoustic array. Although removals could include transmitter failure, based on previous experience it was assumed that transmitter failure would be negligible (Heupel \& Simpfendorfer 2002). The fate of each individual was assigned to one of these categories at the end of each week to construct monitoring histories.

Kaplan-Meier estimation. Survival of juvenile bull sharks was estimated using the nonparametric Kaplan-Meier procedure (Cox \& Oakes 1984, Pollock et al. 1989a,b). This approach computes the proportion of fish that die within the study period and allows for animals that are censored from the population (Pollock et al. 1989b, Heupel \& Simpfendorfer 2002). Three forms of survival were calculated. The first used the number of deaths of animals from all sources of mortality except fishing (referred to as survival from natural mortality). The second method used the number of deaths equal to those censored (removed via fishing), and was referred to as survival from fishing mortality. The third method used both natural and fishing mortalities to calculate survival from total mortality. Differences in survival rates between years were tested with chi-square analysis. Estimates of survival rate were made for periods of 6,12 and 18 mo after birth. These values allowed for comparison with other studies, as well as estimating survival over the life of the acoustic transmitters. To compare the results from the present study with those of previous studies, annualized instantaneous rates of natural mortality were calculated for studies from the literature that determined mortality in $0+$ age classes of sharks using tagging, telemetry or cohort analysis.

Mortality estimation from life history data. Natural mortality was estimated using a range of indirect techniques based on life-history data to provide a comparison with those estimated from telemetry data. Six estimators of constant lifetime mortality (Pauly 1980, Hoenig 1983, Jensen 1996) and one method of age-specific mortality (Peterson \& Wroblewski 1984) were used. All life-history data were taken from Wintner et al. (2002) and Dudley \& Simpfendorfer (2006).

\section{RESULTS}

A total of 59 bull sharks were collected and fitted with transmitters over the course of 3 yr (2003: 18, 8 female, 10 male; 2004: 18, 7 female, 11 male; 2005: 23, 11 female, 12 male). All individuals collected were neonate or young of the year ranging in size from 69 to $98 \mathrm{~cm}$ stretch total length (mean $=80 \mathrm{~cm}$ ) and were monitored within the study site from 1 to $460 \mathrm{~d}$ (Heupel et al. 2010). Although not monitored for the entire time (individuals moved in and out of the acoustic array), days at liberty spanned 1 to 552 . During the $3 \mathrm{yr}$, 5 sharks $(8.5 \%)$ were censored, or removed, from the study site (1 in 2003, 3 in 2004, 1 in 2005). Eight $(13.6 \%)$ cases of natural mortality occurred during the course of the study (1 in 2003, 2 in 2004, 5 in 2005). Most natural mortalities occurred in 2005 and these all occurred within 2 wk of tagging. Natural mortalities in 2003 and 2004 occurred at 8 and 26 wk (in 2004) and 55 wk (in 2003) at liberty.

Calculation of Kaplan-Meier survival estimates varied among years (Fig. 2). Survival estimates were lowest for 2004 because of the higher number of fishing mortalities in that year (Table 1). The first mortality of a monitored shark from the 2003 cohort occurred after more than 12 mo. Fishing mortality was also limited in this population, with only small numbers of animals removed in each year (Fig. 2b). The first natural and fishing mortalities occurred earlier in both 2004 and 2005, but no pattern was apparent in the timing of those events (Fig. 2c).

Pooling data from all years to estimate survival from natural mortality revealed that deaths occurred soon after birth, followed by a levelling off at a rate of approximately 0.7 after 6 mo (Fig. 3a). Survival from fishing mortality also showed a decline soon after birth followed by a level period at a rate of approximately 0.9 after approximately 6 mos (Fig. 3b). The combined effects of fishing and natural mortality resulted in total mortality estimates ranging from 0.11 to 0.37 (Table 1 , Fig. 3c). Comparison of mortality rates between years revealed no significant differences (Table 2).

Bull shark rates of natural mortality from the KaplanMeier method were less than half those of other neonate sharks in nursery areas (Fig. 4), and in one case (school shark Galeorhinus galeus) were an order of magnitude smaller. This indicates a difference in the life history of bull sharks or some ecological advantage over coastal species.

Mortality estimates based on life-history characteristics ranged from 0.08 to $0.17 \mathrm{yr}^{-1}$ (Table 3). Age-independent mortality estimates were almost identical for males and females. Age-specific mortality estimates from the Peterson \& Wroblewski (1984) method declined from $0.21 \mathrm{yr}^{-1}$ for newborn individuals to 

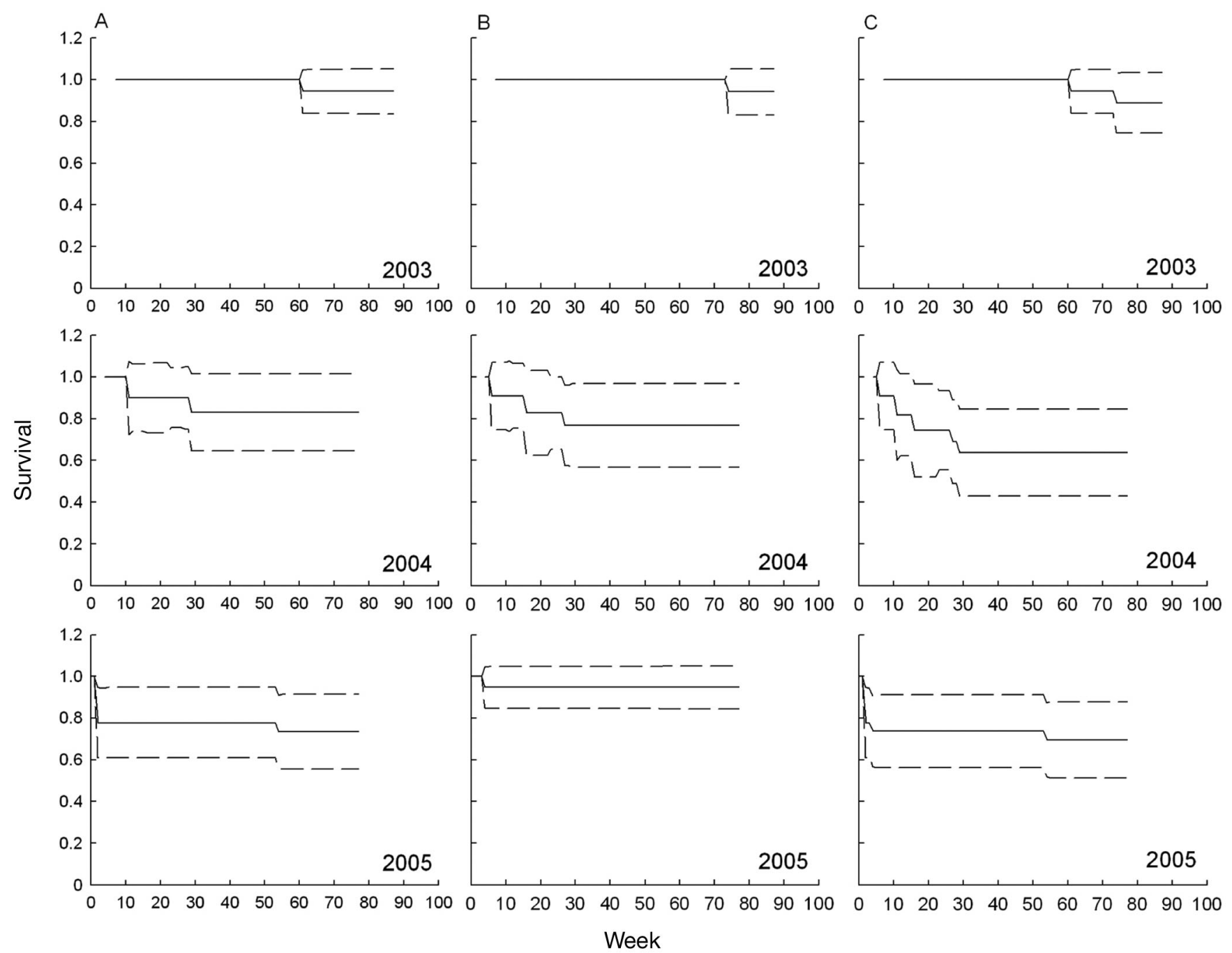

Fig. 2. Kaplan-Meier estimation of survival from (A) natural, (B) fishing and (C) total mortality for juvenile Carcharhinus leucas during 2003-2005. Dashed lines indicate $95 \%$ confidence intervals. All graphs use the week of June 20 as Week 1

$0.09 \mathrm{yr}^{-1}$ at maximum age (32 yr), overlapping the range identified by the age-independent methods.

\section{DISCUSSION}

As concern for exploited marine populations continues to grow, additional data are needed to define the life-history parameters and survivorship of those populations to enable suitable management strategies to be implemented. The results of this study demonstrate that the estuarine areas bull sharks use as nursery habitat provide a low-mortality environment in which the young can live for periods of at least 18 mo. The rates of natural mortality were less than half those of other neonate sharks in marine nursery areas. Some of this difference may be a result of size differences, with neonate school sharks about half the length of neonate bull sharks. However, species such as lemon, tiger and common blacktip sharks are all a similar size to bull sharks at birth and so should have comparable rates of natural mortality if other factors were not important. The main difference between these species is that they occupy different habitats: neonate bull sharks occur in mesohaline estuaries (5 to $18 \mathrm{PSU}$ ) whereas the other species occupy polyhaline estuaries (18 to $30 \mathrm{PSU}$ ) and other coastal marine areas.

The dependence of species on a given habitat has been a topic of discussion for decades (see Able 2005 for a review), but the function of these habitats to the life history of populations that use different juvenile and adult habitats is difficult to define. Beck et al. (2001) and Heupel et al. (2007) provided guidelines to define nursery habitats for fish and shark populations, 
Table 1. Estimates of natural, fishing and total mortality for Carcharhinus leucas derived from Kaplan-Meier survival analysis. Mortality estimates are absolute and provided for 6,12 and 18 mo after birth. Variance estimates are listed in parentheses for 18 mo values

\begin{tabular}{|c|c|c|c|c|c|c|}
\hline $\begin{array}{l}\text { Age } \\
\text { (mo) }\end{array}$ & 2003 & 2004 & 2005 & $\begin{array}{c}\text { Pooled } \\
\text { data }\end{array}$ & $\begin{array}{c}\text { Mean } \\
\text { annualized } \\
\text { mortality }\end{array}$ & $\begin{array}{c}\text { Annualized } \\
\text { pooled } \\
\text { mortality }\end{array}$ \\
\hline \multicolumn{7}{|c|}{ Natural mortality } \\
\hline 6 & 0 & 0.17 & 0.22 & 0.25 & 0.29 & 0.58 \\
\hline 12 & 0 & 0.17 & 0.22 & 0.25 & 0.14 & 0.29 \\
\hline 18 & $\begin{array}{c}0.06 \\
(0.003)\end{array}$ & $\begin{array}{c}0.17 \\
(0.009)\end{array}$ & $\begin{array}{c}0.27 \\
(0.008)\end{array}$ & $\begin{array}{c}0.29 \\
(0.009)\end{array}$ & 0.12 & 0.23 \\
\hline \multicolumn{7}{|c|}{ Fishing mortality } \\
\hline 6 & 0 & 0.17 & 0.05 & 0.10 & 0.15 & 0.21 \\
\hline 12 & 0 & 0.23 & 0.05 & 0.10 & 0.10 & 0.11 \\
\hline 18 & $\begin{array}{c}0.06 \\
(0.003)\end{array}$ & $\begin{array}{c}0.23 \\
(0.011)\end{array}$ & $\begin{array}{c}0.05 \\
(0.003)\end{array}$ & $\begin{array}{c}0.12 \\
(0.006)\end{array}$ & 0.08 & 0.08 \\
\hline \multicolumn{7}{|c|}{ Total mortality } \\
\hline 6 & 0 & 0.36 & 0.26 & 0.33 & 0.50 & 0.80 \\
\hline 12 & 0 & 0.36 & 0.26 & 0.33 & 0.25 & 0.40 \\
\hline 18 & $\begin{array}{c}0.11 \\
(0.005)\end{array}$ & $\begin{array}{c}0.36 \\
(0.011)\end{array}$ & $\begin{array}{c}0.30 \\
(0.009)\end{array}$ & $\begin{array}{c}0.37 \\
(0.009)\end{array}$ & 0.20 & 0.30 \\
\hline
\end{tabular}

respectively. Those studies described the function of nursery habitats for their inhabitants, and one of the criteria set forward is that these regions increase survival. However, nursery habitats are not always restricted to a specific habitat type and, therefore, encompass a broad range of ecotypes. It is unclear whether one nursery performs better than another or how these differences could be quantified. Here, however, we have determined that survival rates of juvenile bull sharks were higher than those of coastal sharks. Each of these species was studied within a nursery ground and each had different natural mortality rates. This result suggests that bull sharks are at an advantage by utilizing habitats not available to species less toler-
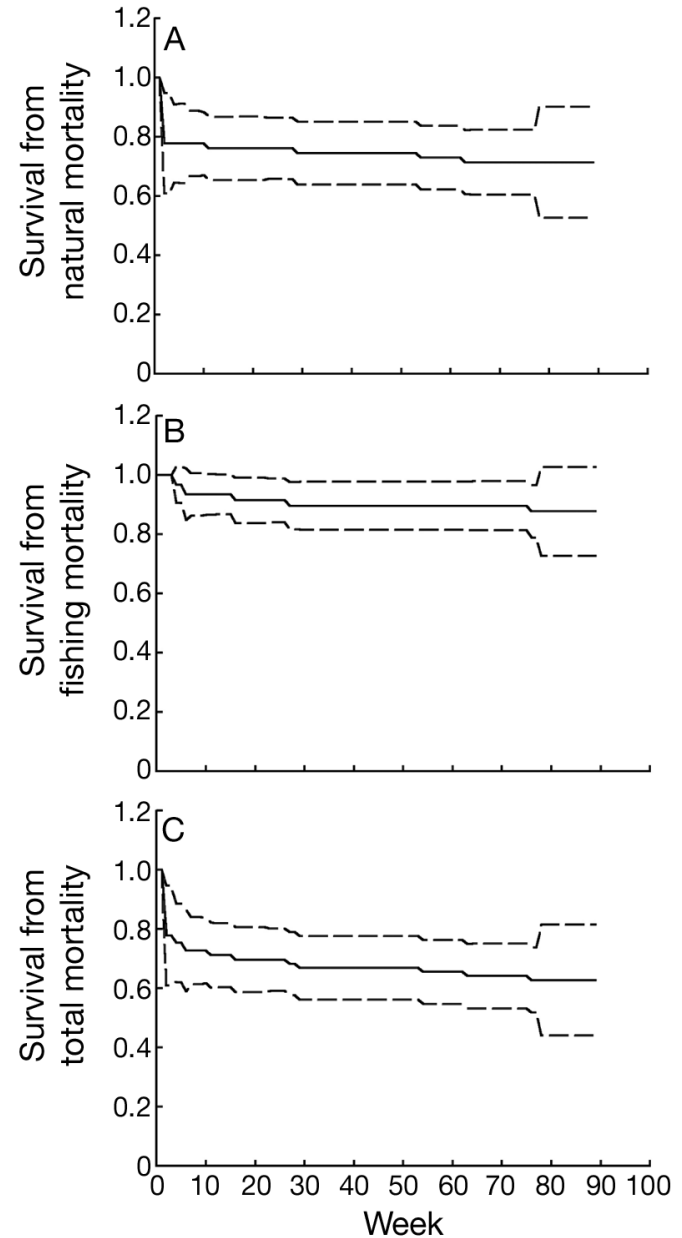

Fig. 3. Kaplan-Meier estimates of survival from (A) natural, (B) fishing and (C) total mortality for juvenile Carcharhinus leucas combined from all 3 years. Dashed lines indicate $95 \%$ confidence intervals. Graphs use the week of June 20 as Week 1
Table 2. p-values from chi-square analysis of Kaplan-Meier estimates of cohort survival of Carcharhinus leucas across years based on natural, fishing and total mortality rates

\begin{tabular}{|lccc|}
\hline & $2003-2004$ & $2004-2005$ & $2003-2005$ \\
\hline Natural mortality & 0.974 & 0.974 & 0.999 \\
Fishing mortality & 0.976 & 0.961 & 0.976 \\
Total mortality & 0.965 & 0.953 & 0.987 \\
\hline
\end{tabular}

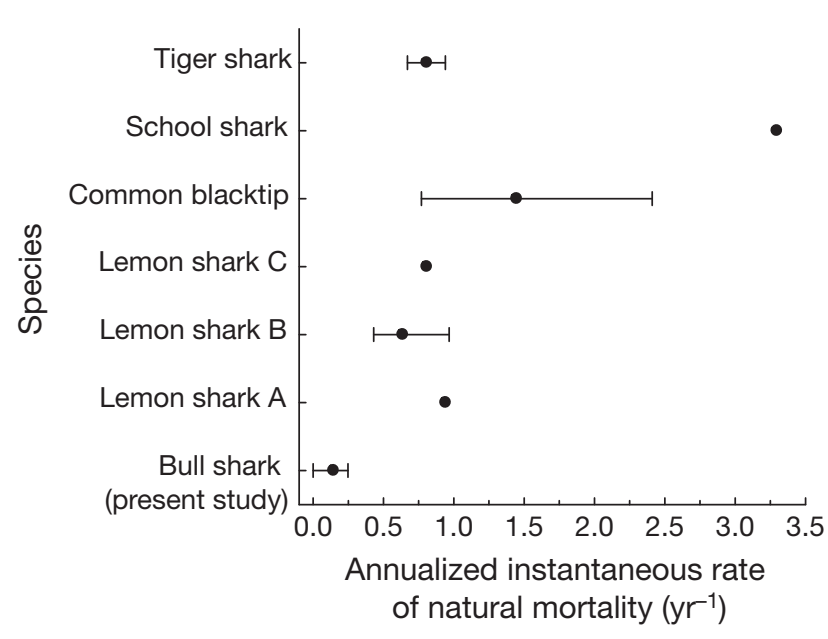

Fig. 4. Comparison of annualized instantaneous rates of natural mortality rates of $0+$ age classes for 5 shark species in 7 studies. Points indicate mean values where data from multiple cohorts were available or point estimates where single values were available. Error bars indicate minimum and maximum values where averages were used. Data for blacktip sharks are from Heupel \& Simpfendorfer (2002), data for lemon sharks are from (A) Manire \& Gruber (1993), (B) Gruber et al. (2001) and (C) de Freitas et al. (2009), data for school sharks are from Xiao et al. (1999) and data from tiger sharks are from Driggers et al. (2008) 
Table 3. Methods used to calculate mortality rates (M: natural mortality; Z: total mortality) for Carcharhinus leucas based on lifehistory parameters. $K$ : Brody growth coefficient (males and females $=0.071 \mathrm{yr}^{-1}$ ); $L_{\infty}$ : maximum length (males and females $=$ $230 \mathrm{~cm}) ; \mathrm{T}$ : mean temperature $\left(25^{\circ} \mathrm{C}\right) ; t_{\mathrm{max}}$ : maximum age (males $=29 \mathrm{yr}$, females $\left.=32 \mathrm{yr}\right) ; x_{\mathrm{m}}$ : age at maturity $($ males $=21 \mathrm{yr}$, females $=20 \mathrm{yr}$ )

\begin{tabular}{|c|c|c|c|}
\hline Method & Relationship & $\begin{array}{l}\text { Mortality } \\
\text { male }\left(\mathrm{yr}^{-1}\right)\end{array}$ & $\begin{array}{c}\text { Mortality } \\
\text { female }\left(\mathrm{yr}^{-1}\right)\end{array}$ \\
\hline Hoenig (1983) (fish) & $\ln (Z)=1.46-1.01 \ln \left(t_{\max }\right)$ & 0.14 & 0.13 \\
\hline Hoenig (1983) (cetacean) & $\ln (Z)=0.941-0.873 \ln \left(t_{\max }\right)$ & 0.14 & 0.12 \\
\hline Pauly (1980) & $\ln (M)=-0.0066-0.279 \log \left(L_{\infty}\right)+0.6543 \log (K)+0.4634 \log (T)$ & 0.17 & 0.17 \\
\hline Jensen (1996) (age) & $M=1.65 / X_{\mathrm{m}}$ & 0.08 & 0.08 \\
\hline Jensen (1996) (growth) & $M=1.5 K$ (theoretical) & 0.11 & 0.11 \\
\hline Jensen (1996) (Pauly) & $M=1.6 K$ & 0.11 & 0.11 \\
\hline
\end{tabular}

ant to freshwater influences. Although the results from the present study were from a single nursery area, the consistent use of mesohaline nursery areas by bull sharks (e.g. Blackburn et al. 2007, Heithaus et al. 2009) suggests that these results are broadly applicable for this species. Thus the ecological strategy of juvenile bull sharks using mesohaline estuarine regions as nursery areas may provide an evolutionary advantage over similar marine species.

There are several potential reasons for increased survival of bull sharks within the Caloosahatchee River, but most of these revolve around predation. Because of the freshwater influence in this system, most large predators are not able to utilize this system and, therefore, predation risk by other species is low. In addition, distribution data for bull sharks along the coast of Florida revealed size-based segregation with the largest individuals found in the fully marine waters of the Gulf of Mexico (Simpfendorfer et al. 2005b). This, in conjunction with the lack of capture of any large bull sharks within the Caloosahatchee River, suggests that cannibalism in this population is rare. With other large predatory sharks unable to tolerate freshwater conditions, predation by larger sharks is unlikely for this population. This scenario contrasts with that of lemon, tiger and common blacktip sharks, which would be exposed to predation by larger members of their own species as well as other species. For example, large hammerhead sharks Sphyrna spp. were observed within the Terra Ceia Bay nursery and, based on telemetry results, presumed to feed on juvenile common blacktip sharks (Heupel \& Simpfendorfer 2002). Similarly, lemon sharks in Bimini, Bahamas, are likely to be preyed upon by larger lemon sharks and other predators in the region (Cortes \& Gruber 1990, Manire \& Gruber 1993). Therefore, predation probably varies among these locations, but appears to be lowest in the Caloosahatchee River. A second factor in determining natural mortality may be competition for resources. Once again, the bull shark population appears to be at an advantage because of the lack of other juvenile sharks and large predatory teleosts. Neonate sharks in nearshore areas are likely competing with other shark species and/or large predators (e.g. barracuda) for food resources. This competition may reduce the ability of naïve individuals to feed themselves, ultimately leading to mortality (e.g. Duncan \& Holland 2006). Therefore, the combination of predation and competition may form the basis for differences in natural mortality rates between different types of shark nursery habitat.

The timing of natural mortality during the first year of life of bull sharks was similar to that of common blacktip sharks (Heupel \& Simpfendorfer 2002), with most occurring in the first month or two after birth. This is likely to be the result of naïve neonate sharks having to learn to find and catch food, and avoid predation. Once outside of this period there is slow but steady mortality. The limited fishing mortality observed for bull sharks made it difficult to draw conclusions about changes in susceptibility to fishing. However, they appear to have a higher susceptibility for a couple of months after birth before settling into a low ongoing rate.

The contrast between the natural mortality rates of neonate bull sharks and those of other species is stark given that the Caloosahatchee River is a highly urbanized river, including canal developments, shoreline development, treated sewage input, heavily managed water flow (Heupel \& Simpfendorfer 2008) and heavy boating traffic. The low mortality rates suggest that the bull shark is able to adapt to urbanized rivers and estuaries quite readily. Little other data are available on the relationship between development and mortality in shark nursery areas. Jennings et al. (2008) reported a $23.5 \%$ decline in survival of neonate lemon sharks in the North Sound of Bimini following extensive development adjacent to this nursery area. As such, bull sharks may be more adaptable to this type of development than other species of sharks.

The low rates of mortality of bull sharks in the Caloosahatchee River also produced different patterns 
of similarity between direct and indirect estimates of mortality when compared with other species of sharks. For example, Heupel \& Simpfendorfer (2002) showed that both age-independent and age-dependent methods underestimated natural or total mortality rates for common blacktip sharks. In contrast, the present study found that age-independent indirect methods produce estimates of a similar magnitude to those from the direct methods whereas the age-dependent method produced overestimates. These contrasting patterns demonstrate some of the limitations of indirect methods for estimating mortality in that they are unable to incorporate habitat-specific effects. As more direct estimates of mortality rates are gathered, it will be possible to model these mortality rates to provide more realistic indirect estimators of mortality that include factors that are not currently included (e.g. habitat type).

Survival of juvenile individuals is crucial to recruitment and maintenance of adult populations (Beck et al. 2001, Gillanders et al. 2003). Although it is intuitive that varying life-history strategies produce differences in survivorship and population levels, the role that habitat use plays in mortality has been more difficult to define. Here we demonstrate that the habitat use strategy of bull sharks provides an evolutionary advantage to this species through utilization of areas unavailable to predators and competitors, which allows increased juvenile survival and, as such, population fitness.

Acknowledgements. This research was funded in part by the Mote Scientific Foundation, South Florida Water Management District and the National Shark Research Consortium (NOAA Fisheries). All research was conducted under IACUC animal ethics permission to M.R.H. The authors thank Mote Marine Laboratory staff who helped with field efforts for this research including B. Yeiser, A. Collins, M. Amato, T. Wiley and J. Morris. We also thank numerous volunteer student interns for their assistance during this project.

\section{LITERATURE CITED}

Able KW (2005) A re-examination of fish estuarine dependence: evidence for connectivity between estuarine and ocean habitats. Estuar Coast Shelf Sci 64:5-17

Bass AJ (1978) Problems in studies of sharks in the Southwest Indian Ocean. In: Hodgson ES, Mathewson RF (eds) Sensory biology of sharks, skates and rays. Office of Naval Research, Department of the Navy, Arlington, VA, p 545-594

Beck MW, Heck KL, Able KW, Childers DL and others (2001) The identification, conservation, and management of estuarine and marine nurseries for fish and invertebrates. Bioscience 51:633-641

Blackburn JK, Neer JA, Thompson BA (2007) Delineation of bull shark nursery areas in the inland and coastal waters of Louisiana. Am Fish Soc Symp 50:331-343

Branstetter S (1990) Early life-history implications of selected carcharhinoid and lamnoid sharks of the northwest
Atlantic. In: Pratt HL, Gruber SH, Taniuchi T (eds) Elasmobranchs as living resources: advances in the biology, ecology, systematics, and the status of the fisheries Proceedings of the second United States-Japan workshop. NOAA Technical Report NMFS 90, p 17-28

Castro JI (1993) The shark nursery of Bulls Bay, South Carolina, with a review of the shark nurseries of the southeastern coast of the United States. Environ Biol Fishes $38: 37-48$

Cortes E, Gruber SH (1990) Diet, feeding habits and estimates of daily ration of young lemon sharks, Negaprion brevirostris (Poey). Copeia 1990:204-218

Cox DR, Oakes D (1984) Analysis of survival data. Chapman \& Hall, New York, NY

de Freitas RHA, Rosa RS, Wetherbee BM, Gruber SH (2009) Population size and survivorship for juvenile lemon sharks (Negaprion brevirostris) on their nursery grounds at a marine protected area in Brazil. Neotrop Ichthyol 7: 205-212

Doering PH, Chamberlain RH (1998) Water quality in the Caloosahatchee Estuary, San Carlos Bay and Pine Island Sound. Proc Charlotte Harbor Public Conf Tech Symp, Tech Rep No. 98.02. Charlotte Harbor National Estuary Program, Punta Gorda, FL, p 229-240

Driggers WB III, Ingram GW Jr, Grace MA, Gledhill CT, Henwood TA, Horton CN, Jones CM (2008) Pupping areas and mortality rates of young tiger sharks Galeocerdo cuvier in the western North Atlantic Ocean. Aquat Biol 2:161-170

Dudley SFJ, Simpfendorfer CA (2006) Population status of 14 shark species caught in the protective gillnets off KwaZulu-Natal beaches, South Africa, 1978-2003. Mar Freshw Res 57:225-240

> Duncan KM, Holland KN (2006) Habitat use, growth rates and dispersal patterns of juvenile scalloped hammerhead sharks Sphyrna lewini in a nursery habitat. Mar Ecol Prog Ser 312:211-221

> Gallaway BJ, Szedlmayer ST, Gazey WJ (2009) A life history review for red snapper in the Gulf of Mexico with an evaluation of the importance of offshore petroleum platforms and other artificial reefs. Rev Fish Sci 17:48-67

Gillanders BM, Able KW, Brown JA, Eggleston DB, Sheridan PF (2003) Evidence of connectivity between juvenile and adult habitats for mobile marine fauna: an important component of nurseries. Mar Ecol Prog Ser 247:281-295

Gruber SH, de Marignac JRC, Hoenig JM (2001) Survival of juvenile lemon sharks at Bimini, Bahamas, estimated by mark-depletion experiments. Trans Am Fish Soc 130: $376-384$

> Heithaus MR, Delius BK, Wirsing AJ, Dunphy-Daly MM (2009) Physical factors influencing the distribution of a top predator in a subtropical oligotrophic estuary. Limnol Oceanogr 54:472-482

Heupel MR, Simpfendorfer CA (2002) Estimation of mortality of juvenile blacktip sharks, Carcharhinus limbatus, within a nursery area using telemetry data. Can J Fish Aquat Sci 59:624-632

Heupel MR, Simpfendorfer CA (2008) Movement and distribution of young bull sharks Carcharhinus leucas in a variable estuarine environment. Aquat Biol 1:277-289

- Heupel MR, Carlson JK, Simpfendorfer CA (2007) Shark nursery areas: concepts, definition, characterization and assumptions. Mar Ecol Prog Ser 337:287-297

- Heupel MR, Yeiser BG, Collins AB, Ortega L, Simpfendorfer CA (2010) Long-term presence and movement patterns of juvenile bull sharks, Carcharhinus leucas, in an estuarine river system. Mar Freshw Res 61:1-10

Hoenig JM (1983) Empirical use of longevity data to estimate mortality rates. Fish Bull 82:898-903 
Hook TO, Rutherford ES, Mason DM, Carter GS (2007) Hatch dates, growth, survival, and overwinter mortality of age-0 alewives in Lake Michigan: implications for habitatspecific recruitment success. Trans Am Fish Soc 136: 1298-1312

Jennings DE, Gruber SH, Franks BR, Kessel ST, Robertson AL (2008) Effects of large-scale anthropogenic development on juvenile lemon shark (Negaprion brevirostris) populations of Bimini, Bahamas. Environ Biol Fishes 83:369-377

Jensen AL (1996) Beverton and Holt life history invariants result from optimal trade-off of reproduction and survival. Can J Fish Aquat Sci 53:820-822

Manire CA, Gruber SH (1993) A preliminary estimate of natural mortality of age-0 lemon sharks, Negaprion brevirostris. In: Branstetter S (ed) Conservation biology of elasmobranchs. NOAA Technical Report NMFS 115, Tampa, FL, p 65-71

Pauly D (1980) On the interrelationships between natural mortality, growth parameters, and mean environmental temperature in 175 fish stocks. ICES J Mar Sci 39:175-192

Peterson I, Wroblewski JS (1984) Mortality rate of fishes in the pelagic ecosystem. Can J Fish Aquat Sci 41:1117-1120

Pollock KH, Winterstein SR, Brunck CM, Curtis PD (1989a) Survival analysis in telemetry studies. J Wildl Manag 53: 7-15

Pollock KH, Winterstein SR, Conroy MJ (1989b) Estimation and analysis of survival distributions for radio-tagged animals. Biometrics 45:99-109

Simpfendorfer CA (1999) Mortality estimates and demographic analysis for the Australian sharpnose shark, Rhizoprionodon taylori, from northern Australia. Fish Bull 97:978-986

Simpfendorfer CA, Milward NE (1993) Utilization of a tropical bay as a nursery area by sharks of the Families Car-

Editorial responsibility: Jana Davis, Annapolis, Maryland, USA charhinidae and Sphyrnidae. Environ Biol Fishes 37: 337-345

Simpfendorfer CA, Bonfil R, Latour RJ (2005a) Mortality estimation. In: Musick JA, Bonfil R (eds) Elasmobranch fisheries management techniques. FAO Fisheries Technical Paper 474, Rome, p 165-185

Simpfendorfer CA, Freitas GG, Wiley TR, Heupel MR (2005b) Distribution and habitat partitioning of immature bull sharks (Carcharhinus leucas) in a southwest Florida estuary. Estuaries 28:78-85

Simpfendorfer CA, Heupel MR, Collins AB (2008) Variation in the performance of acoustic receivers and its implication for positioning algorithms in a riverine setting. Can J Fish Aquat Sci 65:482-492

Snelson FF Jr, Mulligan TJ, Williams SE (1984) Food habits, occurence and population structure of the bull shark, Carcharhinus leucas, in Florida Coastal Lagoons. Bull Mar Sci $34: 71-80$

Springer S (1967) Social organization of shark populations. In: Gilbert PW, Mathewson RW, Rall DP (eds) Sharks, skates and rays. John Hopkins Press, Baltimore, MD, p 149-174

> Thorson TB (1971) Movement of bull sharks, Carcharhinus leucas, between Caribbean Sea and Lake Nicaragua. Copeia 1971:336-338

> Wigington PJ, Ebersole JL, Colvin ME, Leibowitz SG and others (2006) Coho salmon dependence on intermittent streams. Front Ecol Environ 4:513-518

Wintner SP, Dudley SFJ, Kistnasamy N, Everett B (2002) Age and growth estimates for the Zambezi shark, Carcharhinus leucas, from the east coast of South Africa. Mar Freshw Res 53:557-566

Xiao YS, Stevens JD, West GJ (1999) Estimation of fishing and natural mortalities from tag experiments with exact or grouped times at liberty. Can J Fish Aquat Sci 56:868-874

Submitted: February 23, 2011; Accepted: May 2, 2011

Proofs received from author(s): July 11, 2011 